\title{
Plastic Pollution and Climate Change: Role of Bioremediation as a Tool to Achieving Sustainability
}

\author{
S. A. Idowu, D. J. Arotupin, and S. O. Oladejo
}

\section{Contents}

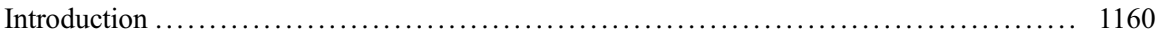

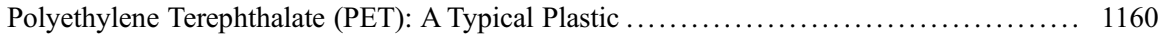

Plastic Waste and Environmental Pollution .................................... 1161

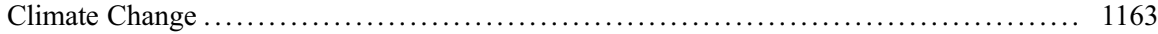

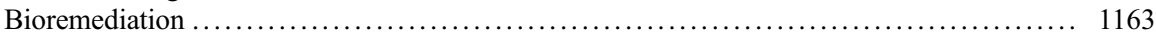

In Situ and Ex Situ Bioremediation ......................................... 1164

Organisms Involved in Bioremediation ....................................... 1164

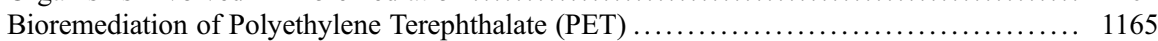

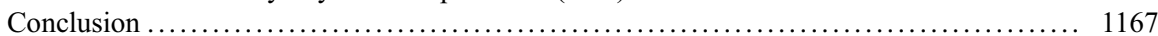

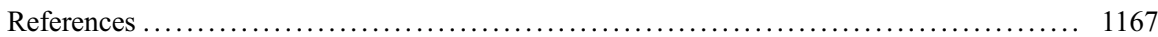

\section{Abstract}

Pollution from post-consumer plastics is a growing global environmental challenge whose negative impacts are exacerbating climate change. Plastics are stable, durable, and hydrophobic. They possess high molecular weight, complex threedimensional structure, and are not readily available to be used as substrate by biological agents such as microorganisms and enzymes. Polyethylene terephthalate (PET) is one of the examples of petrochemical-based plastics. PET is a strong, clear, and light-weight plastic with global usage in the production of bottles.

This chapter was previously published non-open access with exclusive rights reserved by the Publisher. It has been changed retrospectively to open access under a CC BY 4.0 license and the copyright holder is "The Author(s)". For further details, please see the license information at the end of the chapter.

S. A. Idowu $(\bowtie) \cdot$ D. J. Arotupin

Department of Microbiology, Federal University of Technology, Akure, Nigeria

S. O. Oladejo

Department of Remote Sensing and Geoscience Information System, Federal University of Technology, Akure, Nigeria 
Technological innovation, policy formulation, advocacy and sensitization, change in consumption pattern, and bioremediation are some of the approaches that are currently being used to mitigate environmental pollution from post-consumer PET bottles. The ubiquitous property of microorganisms and their ability to survive in almost every environment, including very extreme ones, make them good candidate for biodegradation. Bioremediation is simply defined as engineered or enhanced biodegradation. This review discusses the potential of bioremediation as sustainable and environment-friendly tool to clean up post-consumer PET bottles that already accumulate on land, in soil, and in water bodies.

\section{Keywords}

Bioremediation $\cdot$ Plastic $\cdot$ Pollution $\cdot$ Climate change $\cdot$ Biodegradation

\section{Introduction}

Plastic is a group of substances with wide global usages and applications as a consumer product. Plastic possesses characteristic cheap price, light weight, and disposable nature which make them the substance of choice in the manufacturing industry. However, plastic pollution is a growing global environmental challenge to aquatic, celestial, and terrestrial organisms including man. The current increasing global human population and technological developments are among the major factors contributing to increasing significant snowballing quantity of plastic waste that is generated annually. This increase exacerbates environmental pollution due to unsustainable methods of disposal of post-consumer (or used) plastics. Accumulation of post-consumer plastics on the surface of the earth including those that are buried in the earth is a serious threat to environmental safety and human health. In general, plastics possess characteristic stable, durable, and hydrophobic nature. They possess high molecular weight, complex three-dimensional structure, and are not readily available to be used as a substrate by many biological agents such as microorganisms and enzymes (Arutchelvi et al. 2008; Kale et al. 2015). As a result of the above, plastics accumulate over a very long period of time. (Kenny et al. 2008) reported that an efficient decomposition of plastic takes about 1,000 years.

\section{Polyethylene Terephthalate (PET): A Typical Plastic}

Polyethylene terephthalate (PET) is one of the examples of petrochemical-based plastics. PET is a thermoplastic polyester (Hosseini et al. 2005). It is a strong, clear, and light weight plastic with global usage in the production of bottles. The PET bottles are used for packaging drinks, other food products, and pharmaceuticals. In the field of engineering, PET is being used as alternative or replacement for metals like aluminum, steel, and other metals in the manufacture of precision moldings for office appliances, domestic appliances, and electrical and electronic devices (Hosseini et al. 2005; Tanasupawat et al. 2016; Yoshida et al. 2016). Polyethylene 


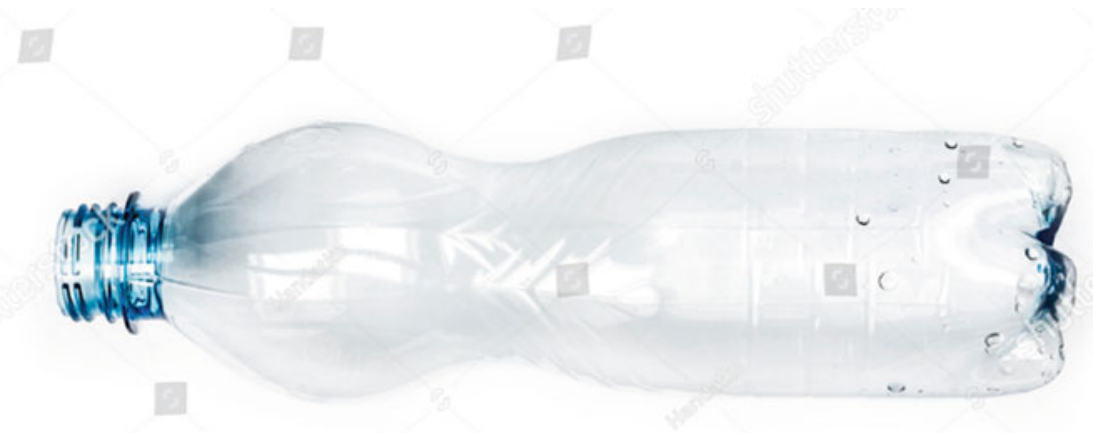

Fig. 1 Typical example of a bottle made from polyethylene terephthalate (PET). (Source: https:// www.shutterstock.com/image-photo/top-view-empty-plastic-bottle-isolated-572688928)

terephthalate is a polyester (polymer) produced by polymerization reaction. The reaction involves two monomers, namely terephthalic acid (TPA) and ethylene glycol (EG) according to (Kale et al. 2015). A typical example of bottle made of PET is presented in Fig. 1 below.

The presence of aromatic groups in the PET molecule makes PET nondegradable under normal condition according to the report of (Hosseini et al. 2005). The biological degradation of PET was thought to be limited to only a few fungal species and as a result biodegradation was earlier considered as not yet a remediation strategy for PET (Tanasupawat et al. 2016).

\section{Plastic Waste and Environmental Pollution}

The traditional methods (such as burning in the open field) used to dispose of postconsumer plastics, especially in developing countries, is a global environmental concern. Smoke, containing dioxins, furans, mercury, and polychlorinated biphenyls which are injurious to health and the environment, is released into the atmosphere during open burning of plastics, thereby leading to air pollution which consequently contributes to climate change (Webb et al. 2013). In addition, most post-consumer PET bottles end up in landfills where they persist and occupy huge land space, thereby impairing soil fertility with subsequent negative impact on agricultural practice (Chan 2016; Kale et al. 2015). Some post-consumer PET bottles are burnt in open fire during which they release carbon dioxide $\left(\mathrm{CO}_{2}\right)$ and dioxins into the atmosphere, also exacerbating environmental pollution and climate change (Kenny et al. 2008; Tanasupawat et al. 2016). Increasing efforts are being made globally to address environmental pollution from PET wastes. Other toxic and hazardous pollutants from plastic wastes are highlighted in the report of (Webb et al. 2013).

Measures and approaches that are currently being used to mitigate plastic pollution include the following: 
- Technological innovations (e.g., bioplastics)

- Policies (e.g., ban of single-use plastics and green shopping)

- Change in consumption pattern and different "Rs" including reduction, reuse, and recycling of post-consumer plastics

- Advocacy/sensitization (e.g., The 2018 World Environment Day with the theme "Plastic Pollution").

- Bioremediation (Gnanavel et al. 2012; Hadad et al. 2005; Hosseini et al. 2005; Ron and Eugene 2014; Sardrood et al. 2013; Yoshida et al. 2016)

It is practically impossible to totally eradicate the use of plastics for domestic and industrial uses, neither is it possible not to generate post-consumer plastics due to vast properties of plastics that make them suitable for various domestic and industrial uses. This therefore means that wastes from post-consumer plastics will be generated continually as long as man exists on earth. This waste is projected to increase with the increasing global human population.

Several approaches have been identified to mitigate environmental pollution from post-consumer plastics. However, two of the approaches are majorly relevant to this discourse. The first is a total removal of PET bottles which constitute environmental nuisance. This can be achieved through sustainable clearing of PET bottles that have been used and dumped, mostly in indiscriminate manner, from the surface of the earth or from water bodies. The second approach is replacing plastics of nonbiological origin with plastics that are made from biological agents. The latter are commonly referred to as bioplastics. Bioplastics are produced or synthesized from biomass or renewable resources according to the report of (Sardrood et al. 2013). They have been identified to be more readily available for bioremediation than nonbioplastics, thereby preventing accumulation on the environment for a very long period of time. Technology is involved in the production of bioplastics to harness the biomass and other raw materials that are employed in the production. This special type of technological process that involves biological agent is called biotechnology (Sardrood et al. 2013). Detailed discussion of types of biotechnology and the processes involved in each of the types are beyond the scope of this chapter.

Technological advancements and scientific researches toward development and improvement on bioplastics are growing globally. This biotechnology will help to produce plastics that will be readily available for easy degradation by microorganisms, thereby proving solution to environmental and climatic problems that are associated with accumulation of post-consumer plastics. As this biotechnology develops to gain worldwide popularity and acceptance to displace nonbioplastics in circulation, it is important to provide suitable sustainable approach to get rid of post-consumer plastics, particularly PET bottles that are already exacerbating environmental pollution and climate change. A biological approach will be appropriate for this remediation as it is usually environment friendly (Gnanavel et al. 2012; Hosseini et al. 2005). The interesting ability of microorganisms to survive in almost every environment including very extreme ones together with their ubiquitous property makes them a good candidate for bioremediation. Bioremediation is a form of biotechnology which involves engineering. This essence of engineering 
the process is to enhance the capacity of the microorganisms being used and to make the process faster (Borasiya and Shah 2007; Hadad et al. 2005).

\section{Climate Change}

Climate change (natural and human induced) is real. Industrialization and human desire for development and better living, which are carried out sometime in an unsustainable way, affect the environment and natural resources negatively, thereby exacerbating climate change. The realization of this challenge by the General Assembly of the United Nations gave birth to establishment of Brundtland Commission. The Commission in their report tagged Our Common Future and submitted to the UN General Assembly in 1987, and identified that both environment and development are inseparable, nevertheless sustainable development must be encouraged in every human development as a means of saving the earth. This development, described popularly as sustainable development, embraces and encourages development that equally promotes economy, social, and environmental developments without prejudice to any of the three members (Burton 1987). Any development whose economic, environmental, and social benefits are not equally addressed is unsustainable and this was part of the recommendation of the commission. Unsustainable consumption of PET bottles is a potential economic, social, and environmental problem that can increase climate change.

\section{Bioremediation}

According to (Baggot 1993; Boopathy 2000) in (Sardrood et al. 2013), bioremediation is a process of using living organisms or biological processes to clean up contaminated environments by exploiting and harnessing metabolic abilities of microorganisms to convert contaminants into harmless products by mineralization, generation of carbon (IV) oxide and water, or by conversion into microbial biomass. Bioremediation as evolving environmental biotechnology uses microorganisms in the degradation process and can be optimized to achieve better result (Borasiya and Shah 2007). Some of the numerous applications of bioremediation include cleanup of ground water, sludges, lagoons, and process-waste stream (Boopathy 2000). Practically, bioremediation has been used on a large-scale application in cleanup of oil spill from Exxon in Prince William Sound, Alaska (Kenny et al. 2008). Some of the advantages of bioremediation have been reported (Boopathy 2000; Sardrood et al. 2013).

Microorganisms have the ability to break the molecular chains in polymers like the PET through degradation. Degradation is one of the many processes involved in bioremediation (Sardrood et al. 2013), this means that a biodegradation activity may not result into total bioremediation. The break in molecular chains during biodegradation leads to decrease in the total length of macromolecules that make the polymer and the degree of polymerization (Fig. 3) as contained in the report of (Hosseini et al. 2005). 


\section{In Situ and Ex Situ Bioremediation}

One of the advantages of bioremediation in management and treatment of wastes is that the process can be carried out at site of contamination or somewhere away from site of contamination. Based on the above, bioremediation can be classified as in situ bioremediation and ex situ bioremediation. The former involves treatment of the contaminated material within the site where contamination or pollution has occurred, while ex situ technique of bioremediation involves physical removal of the contaminant or pollutant from the site of pollution for treatment (Boopathy 2000). In situ bioremediation is usually used in cleanup of oil spills. However, in treating pollutants such as post-consumer PET bottles, ex situ bioremediation may be used.

\section{Organisms Involved in Bioremediation}

Bioremediation involves the use of microorganisms in the remediation process. Pollution from post-consumer plastics can be noticed in the air, on land, and in water bodies such as sea and oceans. The natural ability of microorganisms to degrade hydrocarbons, though at a relatively slow rate, makes them suitable candidates for bioremediation. What scientists do is to simply optimize and harness the natural potential of such microorganisms through biotechnology. (Ron and Eugene 2014; Sardrood et al. 2013) highlight how certain species of microorganisms were used to clean oil spills. Several species of fungi, bacteria, and plants are major organisms that have been identified and reported to be involved in bioremediation. There are specific conditions that enhance bioremediation. The conditions must be provided in order for bioremediation process to proceed as planned and expected. According to (Kenny et al. 2008; Ron and Eugene 2014), these favorable conditions include the following:

1. The organism shall be able to live and demonstrate its bioactivity under conditions of pollution

2. A consortium of microorganism that can successfully utilize the pollutant as a substrate must be present

3. Contaminant and the enzymatic system must come in close contact somewhere in or out of the cell

4. The organisms will have the effective enzymes that are important in bioremediation

5. Appropriate favorable environmental conditions must exist or be provided to enhance multiplication of the potential organism to be used for bioremediation

(Boopathy 2000) summarized the key conditions that affect bioremediation as microbial and environmental substrate, aerobic and anaerobic process, growth substrate and co-metabolism physico-chemical bioavailability of pollutants, and mass transfer limitations. 


\section{Bioremediation of Polyethylene Terephthalate (PET)}

The discovery of the bacterium Ideonellasakaiensis 206-F6 ${ }^{\mathrm{T}}$ signified another scientific development in bioremediation of PET. The discovery presented $I$. sakaiensis as one of the many microorganisms whose potentials can be harnessed to remediate environmental pollution from post-consumer PET bottles that are disposed indiscriminately. The fungus Pseudozymajejuensis isolated from leaves of Citrus unshiu in South Korea earlier before the isolation of I. sakaiensis, has also been demonstrated to possess remarkable plastic-degrading potential as reported by (Tanasupawat et al. 2016). The fungus possesses the enzyme cutinase which has the ability to degrade some plastics according to (Tanasupawat et al. 2016). Despite the plastic-degrading potential of $P$. jejuensis, the organisms were not reported to degrade PET. This development clearly indicates the need to isolate specific microorganisms that are suitable to degrade each of the large groups of plastics that constitute environmental pollution. This necessitated the need for more scientific researches to isolate microorganisms that posses the ability to utilize PET as their source of carbon. The bacterium, I. sakaiensis, is important in bioremediation of post-consumer PET bottles that constitute environmental pollution (Yoshida et al. 2016). According to the report of (Tokiwa et al. 2009; Yoshida et al. 2016), the bacterium showed high PET-degrading potential when compared with previously isolated microorganisms. The authors highlighted factors that favor the bioremediation process in order to achieve optimum result (Fig. 2).

Reports of (Webb et al. 2013; Yoshida et al. 2016) explained that I. sakaiensis $206-\mathrm{F} 6^{\mathrm{T}}$ possesses critical enzymes that are needed in the degradation of PET. The enzymes include PETase and MHETase. I. sakaiensis 206-F6 ${ }^{\mathrm{T}}$ uses the two
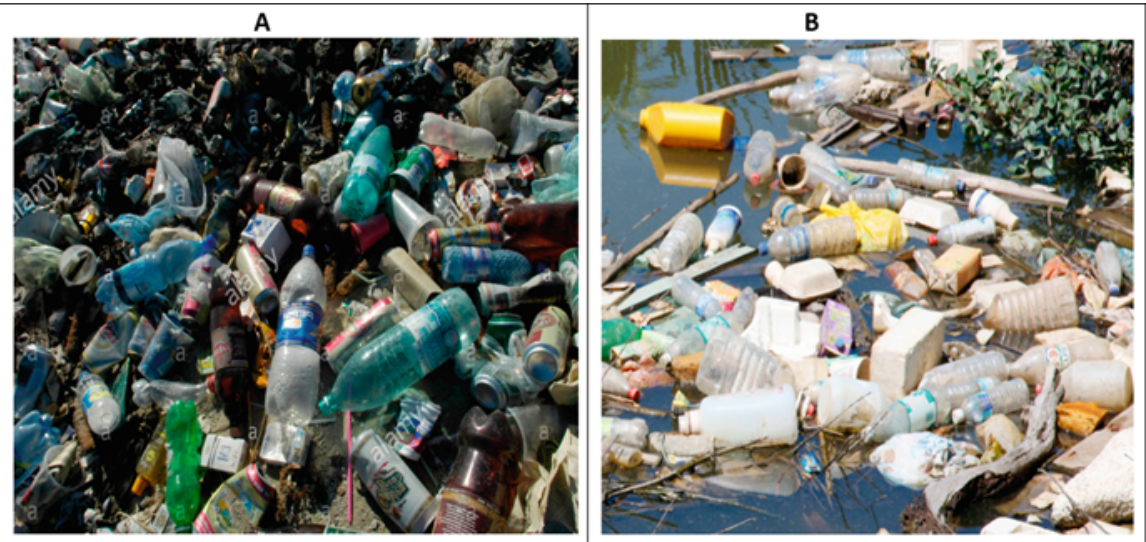

Fig. 2 Images of plastic pollution on both terrestrial and aquatic environment. (a) Dump site showing plastic pollution. (Source: https://www.alamy.com/garbage-dump-plastik-bottles-petbottles-image281712766.html). (b) Plastic pollution of marine environment. (Source: Saving Earth Encyclopaedia Britannica) 


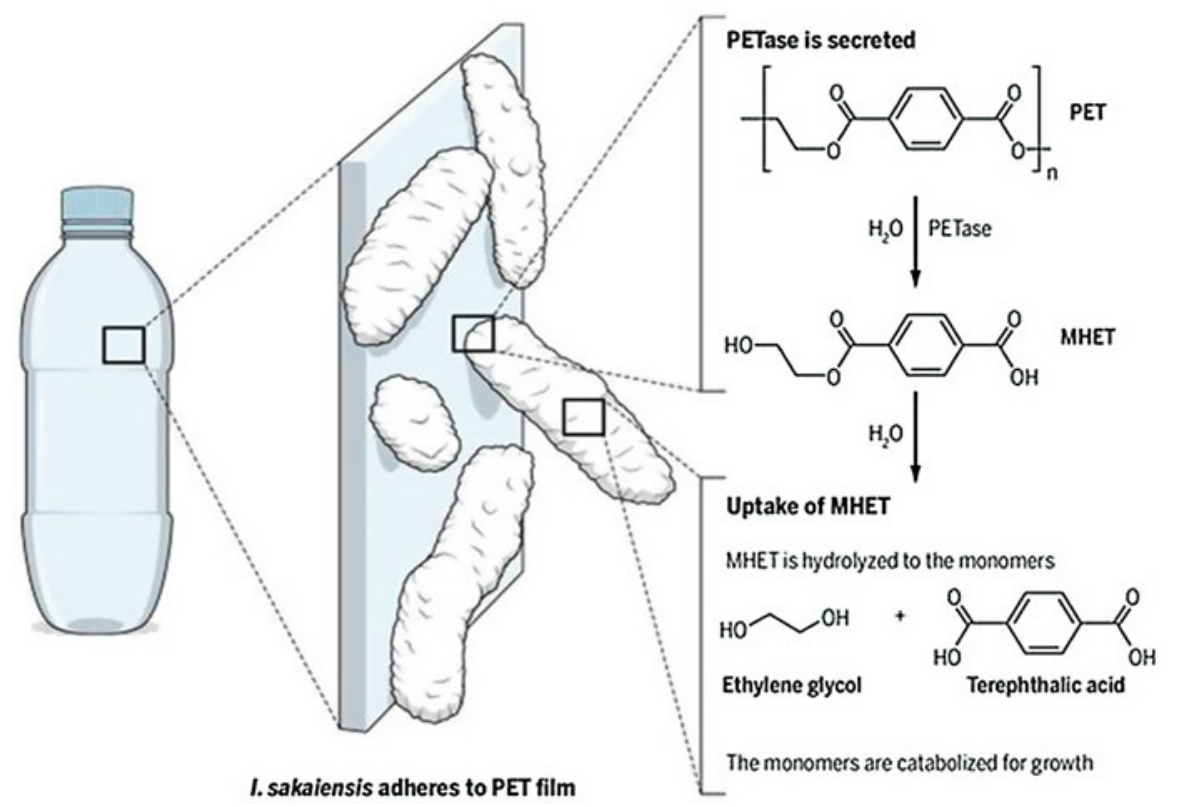

Fig. 3 Schematic degradation of PET bottle by I.sakaiensisstrain 206-F6 ${ }^{\mathrm{T}}$. (Source: (Chan 2016))

enzymes to metabolize PET as its major carbon source (Fig. 3). PETase is a type of esterase and it initiates breaking of the long ester bonds in PET through hydrolytic activity. Esterase is an enzyme that has the ability to break ester bond in a compound. The hydrolytic activity PETase produces an intermediate called mono(2-hydroxyethyl) terephthalic acid (MHET) as presented in Fig. 3 below. The intermediate that results from the hydrolytic breakdown is taken back by the cell of I. sakaiensis 206-F6 ${ }^{\mathrm{T}}$ and is further hydrolyzed by the second enzyme MHETase. The responsibility of MHETase in the degradation process is to break the intermediate into the monomers of PET (Caruso 2015; Tokiwa et al. 2009; Yoshida et al. 2016). The two monomers are named Terephthalic acid (TPA) and ethylene glycol (EG). The report of (Chan 2016) showed that I. sakaiensis 206-

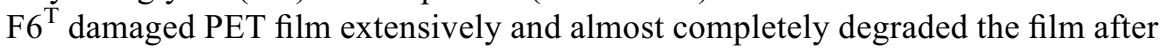
6 weeks at temperature of $30^{\circ} \mathrm{C}$.

In natural environments, PET bottles, like other plastics, are exposed to UV radiation. The radiation causes cleavage of the $\mathrm{C}-\mathrm{C}$ bond of the polymer, thereby leading to the formation of low molecular weight fragments. This process increases the susceptibility of the polymer to microbial attack (Arutchelvi et al. 2008). This may be one of the reasons why (Yoshida et al. 2016) used lowcrystalline (1.9\%) PET film in their study as free-flying plastic bottles in nature may be of a higher crystalline percentage than the ones used by the authors in their research. 


\section{Conclusion}

The above discourse shows that there are several options to reducing environmental pollution from post-consumer plastics in general and PET bottles in specific. However, bioremediation still stands tall as an important evolving option for sustainable remediation of post-consumer plastics. Other approaches such as discouraging unsustainable consumption of plastics and formulation and implementation of research-informed policies also need to be encouraged as a mean to reducing environmental pollution from plastics.

Microorganisms have the natural potential to use petroleum products including plastics as their sources of carbon and energy, thereby helping to reduce the menace of plastic pollution within the environment and subsequently mitigating climate change. The natural potential of microorganisms can be engineered and optimized through biotechnology as the sustainable way to "clean up" plastic pollution that threatens life on land, water, and air.

It is recommended that in order to further contribute to knowledge on harnessing the potential of microorganisms isolated from PET bottle recycling sites to degrade PET bottles, there is the need to test such microbial isolates with PET film of high crystalline value and be sure that the microorganisms can sufficiently hydrolyze the film. This is to ensure wider global acceptability of the technology because the PET bottles that are used to package food, drinks, and pharmaceutical products are made from high crystalline PET.

\section{References}

Arutchelvi J, Sudhakar M, Arkatkar A, Doble M, Bhaddur S, Uppar PV (2008) Biodegradation of polyethylene and polypropylene. Indian J Biotechnol 7:9-22

Baggot J (1993) Biodegradable lubricants. In: Sardrood BP, Goltapeh EM, Varma A (eds) An introduction to bioremediation: fungi as bioremediators. https://doi.org/10.1007/978-3-64233811-3 1

Boopathy R (2000) Factors limiting bioremediation technologies. Bioresour Technol 74:63-67

Borasiya H, Shah MP (2007) Waste water treatment by environmental microbiology. J Bioremed Biodegr. https://doi.org/10.4172/2155-6199.1000386

Burton I (1987) Report on reports: our common future. Environ Sci Policy Sustain Dev 29(5):25-29. https://doi.org/10.1080/00139157.1987.9928891

Caruso G (2015) Plastic degrading microorganisms as a tool for bioremediation of plastic contamination in aquatic environments. J Pollut Eff Cont. https://doi.org/10.4172/2375-4397.1000e112

Chan A (2016) The future of bacteria cleaning our plastic waste. Berkeley Sci J. https://doi.org/10. $5772 / 48612$

Gnanavel G, Valli VPMJ, Thirumarimurugan M (2012) A review of biodegradation of plastics waste. Int J Pharm Chem Sci 1(3):1019-1022

Hadad D, Geresh S, Sivan A (2005) Biodegradation of polyethylene by the thermophilic bacterium brevibacillusborstelensis. J Appl Microbiol 98:1093-1100

Hosseini SS, Taheri S, Zadhoush A, Mehrabani-Zeinabad A (2005) Hydrolytic degradation of poly (ethylene terephthalate). J Appl Polym Sci 102:2304-2309

Kale SK, Deshmukh AG, Dudhare MS, Patil VB (2015) Microbial degradation of plastic: a review. J Biochem Tech 6(1):952-961 
Kenny ST, Runic JN, Kaminsky W, Woods T, Babu RP, Keely CM, Blau W, O’Connor KE (2008) Up-cycling of PET (polyethylene terephthalate) to the biodegradable plastic (polyhydroxyalkanoate). Environ Sci Technol 42(20):7696-7701

Ron E, Eugene R (2014) Enhanced bioremediation of oil spills in the sea. Curr Opin Biotechnol 27:191-194

Sardrood BP, Goltapeh EM, Varma A (2013) In: Goltapeh (ed) Fungi as bioremediators, soil biology. https://doi.org/10.1007/978-3-642-33811-3_1

Tanasupawat S, Takehana T, Yoshida S, Hiraga K, Oda K (2016) Ideonellasakaiensis sp. nov., isolated from a microbial consortium that degrades poly (ethylene terephthalate). Int J Syst Evol Microbiol 66:2813-2818

Tokiwa YA, Calabia BP, Ugwu CU, Aiba S (2009) Biodegradability of plastics. Int J Mol Sci 10:3722-3742

Webb HK, Arnott A, Crawford RJ, Ivanova EP (2013) Plastic degradation and its environmental implications with special reference to poly(ethylene terephthalate). Polymers 5:1-18

Yoshida S, Hiraga K, Takehana T, Taniguchi I, Yamaji H, Maeda Y, Toyohara K, Miyamoto K, Kimura Y, Oda K (2016) A bacterium that degrades and assimilates poly(ethylene terephthalate). Science 351(6278):1196-1199

Open Access This chapter is licensed under the terms of the Creative Commons Attribution 4.0 International License (http://creativecommons.org/licenses/by/4.0/), which permits use, sharing, adaptation, distribution and reproduction in any medium or format, as long as you give appropriate credit to the original author(s) and the source, provide a link to the Creative Commons license and indicate if changes were made.

The images or other third party material in this chapter are included in the chapter's Creative Commons license, unless indicated otherwise in a credit line to the material. If material is not included in the chapter's Creative Commons license and your intended use is not permitted by statutory regulation or exceeds the permitted use, you will need to obtain permission directly from the copyright holder.

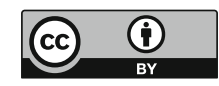

